\title{
Territorio y Medio Ambiente en la Comunidad de Madrid. Nuevos paisajes culturales del agua desde el ámbito demográfico
}

\author{
María SOTELo PÉREZ ${ }^{1}$ \\ Instituto Universitario de Ciencias Ambientales (IUCA/UCM) \\ Departamento de Análisis Geográfico Regional y Geografía Físisca (UCM) \\ Grupo de Investigación: "Desarrollo y Gestión Ambiental del Territorio" \\ maria.sotelo.perez@ucm.es
}

Recibido: 5 de marzo de 2013

Enviado a evaluar: 12 de marzo de 2013

Aceptado: 3 de octubre de 2013

\section{RESUMEN}

Madrid constituye la mayor aglomeración urbana del país, que adopta la forma de "ciudad región", esto es, una gran ciudad formada por un aglomerado urbano central, a modo de área metropolitana, una ciudad dispersa, de una complicada delimitación, y un medio rururbano complejo. Por ello, para aproximarnos a los nuevos paisajes culturales del agua, en la presente investigación analizamos, a partir de las condiciones a que se vio sometido el abastecimiento de agua a Madrid mediante las infraestructuras históricas, el proceso de crecimiento, en un momento inicial, y, de desarrollo, en épocas más recientes, de la población de aquellos municipios por los que transcurren y discurren los Canales llevados a estudio. Por último, señalar que la construcción de las mencionadas infraestructuras tuvo un efecto demográfico indudable, afectando, principalmente, a los núcleos de población ya existentes, dinamizándolos e incrementando el número de sus habitantes de manera progresiva y heterogénea en su distribución geográfica.

Palabras clave: Demografía, Paisajes culturales, agua, Comunidad de Madrid, Medio Ambiente, Territorio.

\section{Land and Environment in the Community of Madrid. New cultural water landscapes from the field population.}

\begin{abstract}
Madrid is the largest conurbation in the country, which takes the form of "city region ", ie a big city made up of a core urban area, as a metropolitan area, a city scattered a complicated definition, and half rururban complex. Therefore, to approach the new cultural landscapes of water, in this research we analyze, from the conditions to which he was subjected to water supply infrastructure through historic Madrid, the growth process at an early stage, and development, more recently, of the population of those municipalities that pass and run the channels carried the study. Finally, note that the construction of these infrastructures had an undeniable demographic effect, affecting mainly the existing population
\end{abstract}

${ }^{1}$ Investigadora en formación. Becaria FPU. 
centers, dynamising and increasing the number of its inhabitants in a progressive and diverse in their geographical distribution.

Key words: Demographic, Cultural Landscapes, water, Madrid, Middle

Planification et de l'environnement dans la Communauté de Madrid. Nouveaux paysages culturels d'eau de la population de la région.

\section{RÉSUMÉ}

Madrid est la plus grande agglomération du pays, qui prend la forme de « ville-région », c'est une grande ville composée d'un pôle urbain, comme une zone métropolitaine, une ville dispersée une définition complexe et demi complexe rururban. Par conséquent, pour Marnos approximatives de nouveaux paysages culturels de l'eau, dans cette recherche, nous analysons, dans les conditions auxquelles il a été soumis à l'approvisionnement en eau infrastructure Madrid par le processus de croissance historique à la fois initiale et, plus récemment, de la population de ces municipalités qui passent et d'exécuter les canaux réalisée l'étude. Enfin, notez que la construction de ces infrastructures a eu un effet démographique indéniable, affectant principalement les centres urbains existants, dynamiser et en augmentant le nombre de ses habitants dans une progressive et diversifiée dans leur répartition géographique.

Mots-clés: Démographiques, les paysages culturels , l'eau, la Communauté de Madrid, environnementaux territoire.

\section{INTRODUCCIÓN: EL AGUA Y LAS NUEVAS JERARQUÍAS GLOBALES DE PRODUCCIÓN}

El agua es un recurso limitado, aunque creamos lo contrario, puesto que no todo el mundo tiene acceso a este bien tan preciado y tan necesario para la supervivencia humana. La disponibilidad de consumo o abastecimiento de agua, ha sido el centro principal de los asentamientos de las poblaciones, en unos u otros emplazamientos, como punto de referencia para la supervivencia de sus gentes y como núcleo de partida del desarrollo de las distintas actividades económicas. El problema principal de este bien es la escasez puesto que, en la mayoría de los casos, las demandas de agua exceden sustancialmente a la propia oferta natural del agua (Sotelo Pérez, M., 2012).

A lo largo de los últimos años asistimos a una cierta revalorización del papel que ejerce el espacio en el análisis socio-económico, en el ámbito del tema estudiado. Los procesos de reestructuración productiva y globalización socioeconómica en curso de realización están asociados a transformaciones espaciales de primer orden, por lo que es necesario alcanzar nuevos enfoques en los análisis de las consecuencias que las nuevas realidades generan. A esto hay que añadir que es necesario diseñar nuevas políticas y estrategias de actuación más imaginativas y dinámicas que, basadas en la racionalidad y la solidaridad, ofrezcan soluciones viables. Se superan así visiones tradicionales y simplistas en las que el espacio era entendido sólo como mero escenario que actuaba de soporte para el desarrollo de los procesos sociales y económicos y, cada vez más generalizadamente, los científicos sociales, desde diversas interpretaciones y disciplinas, consideran al espacio como un elemento activo que constituye 
una parte importante de tales procesos y que contribuye, además, a la generación de ventajas competitivas.

Con estos planteamientos de partida se están realizando análisis, desarrollando tesis e incorporando categorías conceptuales a las nuevas lógicas de articulación territorial asociadas a las transformaciones socioeconómicas. Como señala Boisier, "nada ni nadie parece escapar a la máquina de los cambios..., ¿por qué no habrían de cambiar los conceptos y el modo mismo de generación y funcionamiento de los territorios organizados?" (Boisier, S., 1995, 5). La mayor parte de los análisis se centran básicamente en la relación innovación/globalización/territorio, considerando que en tales procesos se encuentra la clave de los cambios en las formas de acumulación, de la actual organización de las sociedades y de "la emergencia de una nueva Geografía del desarrollo capitalista" (Harvey, D., 1996, 245). Es en este ámbito en el que variables como el agua desempeñan un papel cada vez más decisivo.

Por otra parte, señalar que la concentración territorial del capital es una de las consecuencias más claras de la nueva dinámica económica. A su vez, su concentración y localización selectiva podría explicarse por niveles distintos de fertilidad de los territorios. De esta manera, los más fértiles son y serán los que concentren mayores volúmenes de capital circulante. En este mismo sentido, el capital no tiende a localizarse en los lugares más desregulados y con costos salariales más bajos sino que resulta atraído por factores que están estrechamente vinculados a la historia productiva del lugar y que parecen contribuir mejor a su reproducción. Entre estos factores, podemos destacar: el ambiente económico, entendido como la multiplicidad y profundidad en la disponibilidad de insumos, tecnologías, conocimiento, mano de obra calificada, servicios, información, nuevos conocimientos, etc.; la infraestructura física, determinada por la presencia de electricidad, agua, disposición de desperdicios, sistemas de transporte y comunicación, entre otros; la infraestructura pública provista por la presencia de un sistema judicial, administrativo y regulatorio; los patrones culturales de interacción social; la infraestructura social (educación, seguridad social, etc.), y finalmente, la estabilidad política, institucional y económica. Así, la localización conjunta de estos factores es determinante -tanto en la escala global como localen la distribución territorial de la producción y, consecuentemente, de los respectivos mercados de trabajo que finalmente orientan los movimientos de población.

A partir de este proceso de organización territorial, se produce lo que podría definirse como un círculo vicioso, en el cual la presencia de los factores antes mencionados atrae la localización de actividades económicas y de población. A su vez, esto determina una mayor acumulación de capital por parte de estos lugares, con el consecuente incremento de las potencialidades de la fuerza de trabajo, de la producción de conocimientos y de la capacidad empresarial. Todo esto tiende a perpetuar e incrementar la aptitud que estos territorios tienen para atraer al capital circulante, acentuando su concentración y produciendo una mayor discontinuidad territorial.

Esta nueva organización territorial presenta formas urbanas bien definidas que se distinguen de aquéllas que caracterizaron al proceso de modernización. Quizás la más relevante sea la "metropolización", que consiste en el avance de la mancha urbana sobre áreas rurales y "rururbanas", incorporando, además, otros centros urbanos 
preexistentes, próximos a las áreas metropolitanas en expansión. De esta manera, la estructura urbana resultante presenta una ciudad central densa y compacta con una periferia que incorpora subcentros y va disminuyendo progresivamente su grado de consolidación, fundiéndose sus límites con el entorno rural y semirural "no metropolitano". Algunos autores identifican a esta forma de organización metropolitana con una geografía urbana de archipiélagos, en la cual la metrópolis es susceptible de ser leída como un conjunto de territorios insulares.

De esta manera, los contextos que marcan la puesta en práctica de las nuevas políticas de desarrollo regional los hallamos en el hecho de que el modelo de red guía la nueva organización territorial -a partir de los procesos anteriormente señalados- de la producción. En este sentido, disminuye la importancia relativa de las distancias, la cooperación productiva y la eficiencia dejan de depender de los grados de proximidad y de la centralización territorial. Esta tendencia es aún más pronunciada en el proceso de trabajo inmaterial que involucra la manipulación de conocimiento e información. En el trabajo de producción informacional (tanto de servicios como de bienes) se le otorga un rol central a la comunicación de conocimientos e información entre trabajadores sin que ello implique su presencia, y hasta pueden ser desconocidos o conocerse sólo a través del intercambio de información productiva.

En este nuevo escenario surgen un conjunto de actividades cuyo insumo principal es la información basada en el conocimiento. Esas actividades están contribuyendo a que se diluyan los tradicionales límites entre sectores de la economía, sea porque aparecen en las zonas fronterizas entre industria y servicios, por ejemplo, o porque transforman el núcleo de actividades tradicionales existentes. En el conjunto de las actividades vinculadas al nuevo paradigma, entre las que se destacan las telecomunicaciones y la informática, también se incluyen las denominadas "industrias culturales" que están asociadas a los medios masivos de comunicación tales como la producción de televisión, video, cine, música digital y diseño gráfico e impresión, entre otras. Así, la competencia entre regiones por alcanzar las posiciones relativas de nivel medio en la jerarquía global no es conducida ya a través de la industrialización sino de la informatización de la producción.

Las tendencias hacia la desconcentración de la producción y el aumento en la movilidad del capital están acompañados por una concentración territorial del control sobre la producción, en especial si consideramos este proceso desde una perspectiva global. Así, pues, no son pocos los estudiosos que afirman que nos encontramos ante la construcción de un nuevo orden económico que se despliega de manera desigual y de forma contradictoria en todas las áreas del mundo. En este marco, las nuevas tecnologías constituyen el principal soporte material para la integración de los procesos económicos a nivel mundial, al mismo tiempo que cobra mayor importancia el rol de las ciudades como soporte material de los procesos productivos estructurados e integrados globalmente. Las tendencias masivas hacia la dispersión espacial de las actividades económicas en los niveles metropolitano, nacional y global asociados a la globalización han contribuido con la demanda por nuevas formas de centralización territorial de la gestión de alto nivel y de control de las operaciones, debido a que esta dispersión está ocurriendo en condiciones de concentración del control, la propiedad 
y la asignación de las utilidades, desempeñando el abastecimiento de agua un papel que podríamos calificar de fundamental. Los mercados nacionales y globales, como también las organizaciones globalmente integradas, requieren de lugares centrales donde el trabajo de la globalización pueda realizarse. Luego, las industrias de información requieren una vasta infraestructura física que contenga nodos estratégicos con una hiperconcentración de servicios. En tal sentido, hay que distinguir entre la capacidad de transmisión/comunicación global y las condiciones materiales que hacen esto posible.

Para conseguir integrarse con una buena posición en el sistema mundo se produce una creciente competencia interterritorial que hace necesario -no ya sólo a las empresas, sino también a los distintos ámbitos- aprovechar sus propias ventajas y potencialidades. En relación con lo anterior, ciertos aspectos resultan de interés: por una parte, se acepta que la competitividad en la nueva economía-global se ve determinada por la capacidad para desarrollar innovaciones; por otra, hay que tener en cuenta que la emergencia de determinados ámbitos se basa sobre todo en las interacciones entre los actores y en su capacidad para desarrollar proyectos comunes que aporten soluciones a sus problemas. Asimismo, se revalorizan e identifican recursos alternativos, generalizándose la tesis de que todo proceso de desarrollo requiere la utilización imaginativa, racional, equilibrada y dinámica de todos los bienes patrimoniales, sean estos monetarios, humanos, naturales, sociales, culturales o territoriales.

Por otra parte, a pesar de las transformaciones ocurridas en los últimos años y de la volatilidad creciente de las economías actuales, el territorio europeo presenta, en términos generales, una gran inercia. Difícilmente se conseguirá imaginar la emergencia de patrones territoriales completamente nuevos e implicando la anulación de las realidades anteriormente prevalecientes, inclusive en áreas tan dinámicas como la región central del espacio comunitario, comprendida entre Londres/Amsterdam/Colonia/París (European Union, 1996). Las incidencias recientes y previsibles sugieren, aún así, algunas situaciones donde el cambio será ciertamente más intenso:

Las grandes ciudades, caracterizadas por una rápida rotación de usos de suelo de las áreas tanto intraurbanas (regeneración del centro) como periurbanas (creación de nuevas centralidades); Los corredores que conectan las principales aglomeraciones urbanas, desde que vienen servidos por las nuevas redes de transporte y telecomunicaciones (los "eurocorredores" en el caso del espacio comunitario); Las regiones fronterizas donde se afirman relaciones de interacciones significativas entre ambos lados de la frontera; Las áreas rurales mucho más valoradas por su cualidad ambiental y patrimonial, sobre todo las que fueron blanco de políticas eficaces de conservación de la naturaleza.

Paralelamente, y desde un punto de vista negativo, ocurrieron situaciones de creciente "periferización" en relación a las aglomeraciones y regiones provistas de una posición excéntrica frente a las nuevas redes de transportes y telecomunicaciones. En términos de grandes patrones de organización territorial, la tendencia parece ser más de continuidad, expansión e intensificación que de ruptura e inflexión. El contexto prevaleciente parece ser, por tanto, de una relativa inercia espacial. Podría pensarse 
que esta situación es susceptible de ser contrariada a través de intervenciones voluntaristas con impacto real sobre la organización del territorio. A este propósito conviene invocar, una vez más, el artículo recientemente publicado por Jayet, Puig y Thisse (1996). Se refieren los autores, a propósito de los sistemas urbanos, que no sólo es muy difícil pasar radicalmente de un determinado tipo de estructura (centralizada, por ejemplo) hacia otra (jerárquica y equilibrada); con esa mudanza, el proceso puede correr el riesgo de debilitar los factores económicos que garantizan la eficacia del primer tipo, sin conseguir, al mismo tiempo, consolidar los nuevos factores necesarios para la emergencia del segundo tipo de estructura. La conclusión resultante de esta observación parece obvia: la única manera de evitar intervenciones que se limiten a prolongar y a profundizar situaciones ya dominantes o acciones que introduzcan mudanzas radicales social e institucionalmente incontrolables, es ser muy selectivo en las intervenciones a efectuar. Esta selectividad, a su vez, implica una visión estratégica concertada y socializada en lo que se refiere a los objetivos a alcanzar, a los actores a movilizar y a los medios e instrumentos a utilizar. Detengámonos en el estudio y valoración del abastecimiento de agua a Madrid, como estudio de caso, desde una perspectiva demográfica, en sus implicaciones socioeconómicas.

\section{ESTUDIO DE CASO: POBLACIÓN Y RECURSOS DEL AGUA, EN LA COMUNIDAD DE MADRID}

Hoy en día el agua se encuentra al alcance de la mayor parte de la población, aunque hasta hace poco la realidad era bien distinta. El agua se ha convertido en un bien tan accesible en la sociedad actual que a veces olvidamos porqué sale a través de un grifo, o donde va una vez escapa por el desagüe. Tampoco se reflexiona sobre lo necesaria que puede llegar a ser para el desenvolvimiento de la humanidad. Además puede considerarse el agua como un elemento "vivo", por su naturaleza cambiante, por su movilidad, por los distintos estados en que se manifiesta y su facilidad de interrelación con otras sustancias y elementos. Su composición y características junto con el desarrollo evolutivo de las distintas especies animales y vegetales, han hecho que resulte imprescindible a la hora de valorar el concepto de vida, por lo que cabe concluir que la "vida" del agua se encuentra íntimamente relacionada con la de los seres vivos. Pero, al mismo tiempo la naturaleza del agua se ve alterada por el ciclo vital humano, al igual que las modificaciones que pueda sufrir esta influyen necesariamente en los demás seres vivos y en el medio ambiente; por ello el agua es uno de los elementos que une a las personas y a la naturaleza (citar art.)

El abastecimiento incluye los servicios de aducción y de distribución. En general, suele ser asumido por los Ayuntamientos, pero por razones históricas, en el caso de Madrid, se encomienda la gestión integral al Canal de Isabel Segunda (CYII), ente dependiente de la Comunidad Autónoma madrileña. Y es que Madrid dispone de una red de infraestructuras y de distribución bien desarrollada que además de ofrecer un buen servicio, eleva las garantías de suministro y el control de la demanda. El servicio de abastecimiento es gestionado por el Canal de Isabel II, el cual dispone de profesionales expertos en la gestión del agua, a todos los niveles, y con un alto grado de 
especialización, lo que redunda en la calidad del servicio. El conocimiento que se tiene del sistema sus combinaciones y alternativas permite una gran flexibilidad en la gestión del recurso. (Sotelo Pérez, M., 2013)

Todo ello desde la idea de que podemos señalar que nuestra zona de estudio se encuentra en su integridad, formando parte de la Cuenca del río Tajo. En España, en general, y en la cuenca del río Tajo, en particular, la naturaleza se nos presenta marcada por la acción del hombre, que desde tiempos primigenios ha influido sobre la realidad del medio, transformando los espacios naturales. Sin lugar a dudas, nuestra zona de estudio se encuentra ante una de las cuencas hidrográficas más importante de la Península, por su extensión y por su caudal, la del río Tajo. La cuenca es una fosa tectónica que podríamos calificar de modélica. Dos moles montañosas, el Sistema Central y los Montes de Toledo en sentido amplio, la flanquean al Norte y al Sur. La dovela hundida, formada por idénticos materiales que las Sierras, granitos y gneis, alcanza una gran profundidad. Al Este el Sistema Ibérico castellano, principalmente calizo y mesozoico, cierra Castilla y la cuenca del Tajo, viniendo a dar vida con el agua de sus nieves a un Tajo "niño". Además, consecuencia de la colmatación con materiales provenientes del desmoronamiento de los potentes relieves contiguos, durante un largo período geológico, en ella se formaron numerosas lagunas, poco a poco, desecadas. Su abundancia procede de los afluentes de la margen derecha, entre los que destacan: el río Gallo, que recoge las aguas de la comarca de Molina, el sistema Henares-Jarama, que drena las aguas del sector central y oriental del Sistema Central, el Alberche, que tiene su origen en la sierra de Gredos, y tantos otros (citar art.).

Figura 1. Localización de la zona de estudio.

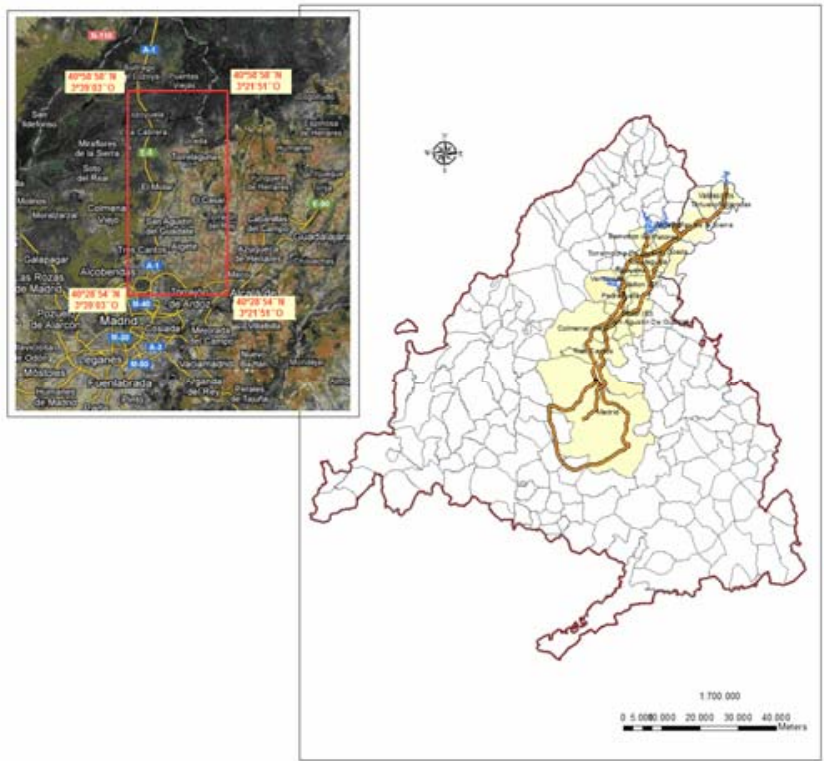

Fuente: Sotelo Pérez, M. (2013). 
El territorio estudiado se circunscribe a la Comunidad de Madrid, y al espacio que limita con la zona nororiental de la Comunidad de Castilla-La Mancha, en la provincia de Guadalajara, circunscrito al curso de una de sus principales arterias fluviales: el río Jarama y sus afluentes (especialmente, el Lozoya). Abarca, por tanto, los dos grandes dominios geológicos regionales constituyentes de este territorio, el Sistema Central y la cuenca mesocenozoica del Tajo o de Madrid. Nuestro objetivo fundamental es estudiar las conducciones de agua (sifones) que permiten abastecer a Madrid (Canales del Villar, de la Parra, del Lozoya, Alto y Bajo). En la figura 1 podemos observar que la zona por la que se extienden las conducciones que estamos estudiando, se encuadra entre los $40^{\circ} 58^{\prime} 58^{\prime \prime}$ y los $40^{\circ} 28^{\prime} 54^{\prime \prime}$ a latitud norte, y, los $3^{\circ} 39^{\prime} 03^{\prime \prime}$ y los $3^{\circ} 21^{\prime} 51^{\prime \prime}$ de longitud oeste; comprende los términos municipales de Madrid, Tres Cantos, Alcobendas, Colmenar Viejo, San Agustín de Guadalix, La Cabrera, El Molar, Pedrezuela, Redueña, Vellón, Venturada, Torrelaguna, Torremocha del Jarama, Patones y el Berrueco en la Comunidad Autónoma de Madrid.

\subsection{LAS DINÁMICAS DEMOGRÁFICAS}

El desarrollo demográfico implica un aumento de las exigencias de aprovisionamiento de agua en el entorno próximo, con lo que ello implica de adaptación de las estructuras productivas a una demanda anónima e imprevista (Valenzuela, M., 1987). Dadas las condiciones a que se vio sometido el abastecimiento de agua a Madrid, el proceso de crecimiento, en un momento inicial, y, de desarrollo, en épocas más recientes, de la población de aquellos municipios por los que transcurren y discurren los Canales objeto de estudio en el presente trabajo, ha estado marcado por la construcción de las infraestructuras del Canal de Isabel II.

Por otra parte, señalar que las infraestructuras que estamos estudiando son un elemento más de la acción antrópica en la Región de Madrid es intensa y dilatada tanto en el tiempo como en el territorio, con espacios regionales totalmente antrópicos (urbanos y metropolitanos). Por el contrario, el ámbito rururbano y rural presentan la singularidad que han introducido hechos culturales, económicos y estéticos que de algún modo han quedado grabados en el paisaje, o bien, aleccionan su interpretación y definición. No podemos olvidarnos que, la naturaleza considerada como recurso, es decir, el medio natural está sometido a las actividades humanas pasando a ocupar un posición secundaria, por lo que a su uso y aprovechamiento, en muchas ocasiones, queda reducido a un limitado número de factores medioambientales.

\subsubsection{DISTRIBUCIÓN Y EVOLUCIÓN DE LA POBLACIÓN}

La construcción del Canal de Isabel II tuvo un efecto demográfico indudable, afectando, principalmente, a los núcleos de población ya existentes (ya que no existen asentamientos importantes de nueva planta surgidos a partir de la creación de dichos canales), dinamizándolos e incrementando el número de sus habitantes de manera progresiva y heterogénea en el territorio. 
De hecho no son pocas las diferencias demográficas entre los distintos municipios que conforman nuestra área de estudio, destacando por sus elevados niveles de población, los más meridionales, Madrid (con más de tres millones de personas) y Alcobendas (que supera los cien mil habitantes). Mientras que los municipios septentrionales como El Berrueco, Patones, Redueña y Torremocha del Jarama, presentan niveles poblacionales inferiores a los 1.000 habitantes (este contraste se ve subrayado por el hecho de las distintas demandas de agua de los mismos). (Ver figura 2).

Figura 2. Características demográficas del área de estudio.

\begin{tabular}{|c|c|c|c|c|c|c|c|}
\hline \multirow[b]{2}{*}{ Características } & \multirow[b]{2}{*}{ Superficie $\left(\mathrm{km}^{2}\right)$} & \multirow{2}{*}{$\begin{array}{l}\text { Densidad de Población } \\
(\text { hab./km²) a 1-1-2012 }\end{array}$} & \multirow[b]{2}{*}{ Población a 1-1-2012 } & \multicolumn{4}{|c|}{ Población municipal, por grupos de edad, a 1-1-2012 } \\
\hline & & & & De 0 a 14 años & De 15 a 64 años & De 65 a 74 años & De 75 y más \\
\hline Alcobendas & 45,27 & 2452,84 & 111.040 & 18.424 & 79.066 & 8.320 & 5.230 \\
\hline El Berrueco & 28,43 & 21,32 & 606 & 89 & 415 & 41 & 61 \\
\hline La Cabrera & 22,16 & 115,75 & 2.565 & 419 & 1.780 & 189 & 177 \\
\hline Colmenar Viejo & 182,98 & 253,15 & 46.321 & 8.366 & 32.662 & 2.488 & 2.805 \\
\hline Madrid & 604,98 & 5344,85 & 3.233.527 & 438.112 & 2.168 .551 & 284.258 & 342.606 \\
\hline EI Molar & 50,21 & 163,83 & 8.226 & 1.486 & 6.009 & 377 & 354 \\
\hline Patones & 35,06 & 14,86 & 521 & 52 & 322 & 44 & 103 \\
\hline Pedrezuela & 28,55 & 175,83 & 5.020 & 995 & 3.626 & 195 & 204 \\
\hline $\begin{array}{c}\text { Redueña } \\
\text { San Agustín de }\end{array}$ & 13,04 & 22,32 & 291 & 60 & 176 & 38 & 17 \\
\hline Guadalix & 38,27 & 333,68 & 12.770 & 2.854 & 9.095 & 430 & 391 \\
\hline $\begin{array}{c}\text { Torrelaguna } \\
\text { Torremocha del }\end{array}$ & 43,09 & 112,79 & 4.860 & 825 & 3.327 & 304 & 404 \\
\hline Jarama & 18,92 & 46,35 & 877 & 137 & 557 & 67 & 116 \\
\hline El Vellón & 33,51 & 52,64 & 1.764 & 265 & 1.205 & 127 & 167 \\
\hline Venturada & 10,23 & 185,43 & 1.897 & 376 & 1.331 & 124 & 66 \\
\hline Tres Cantos & 37,96 & 1088,04 & 41.302 & 7.553 & 30.184 & 1.945 & 1.620 \\
\hline
\end{tabular}

Fuente: Elaboración propia, a partir de los datos del Instituto de Estadística de la Comunidad de Madrid y del Instituto Nacional de Estadística.

Sin lugar a dudas, lo anteriormente expuesto se ve complementado por unas zonas cuya demanda de agua está íntimamente relacionada con la densidad de población. De los datos recogidos se colige que tan solo los municipios de Madrid (5.344,85 hab. $\left./ \mathrm{km}^{2}\right)$, Alcobendas $\left(2.452,84 \mathrm{hab} . / \mathrm{km}^{2}\right)$ y Tres Cantos $\left(1.088,04 \mathrm{hab} . / \mathrm{km}^{2}\right)$ presentan una altísima densidad demográfica, superior incluso a los 1.000 habitantes por kilómetro cuadrado. En contraposición, los términos municipales de El Berrueco $\left(21,32 \mathrm{hab} . / \mathrm{km}^{2}\right)$, Patones $\left(14,86 \mathrm{hab} . / \mathrm{km}^{2}\right)$, Redueña $\left(22,32 \mathrm{hab} . / \mathrm{km}^{2}\right)$ y Torremocha del Jarama $\left(46,35 \mathrm{hab} . / \mathrm{km}^{2}\right)$ no llegan al medio centenar de habitantes por kilómetro cuadrado.

De igual modo, destacar el caso de Tres Cantos (municipio que perteneció a Colmenar Viejo hasta el año 1986), ya que, a pesar de tener una superficie territorial inferior al municipio de Colmenar viejo, su nivel de población es prácticamente la misma y, por ende, presenta una densidad de población superior $\left(1.088,04 \mathrm{hab} . / \mathrm{km}^{2}\right)$.

Por otro lado, si descendemos al estudio pormenorizado de la estructura etaria, observamos claras diferencias territoriales. Ejemplo de ello lo encontramos en los términos municipales de Pedrezuela, Redueña, San Agustín de Guadalix y Venturada que poseen una población joven, ya que más del $20 \%$ de sus habitantes tienen menos de 15 años; mientras que en Patones y Torremocha del Jarama, el 21\% de su población tiene más de 65 años (y, en el caso concreto de Patones, más del $20 \%$ de sus habitantes supera los 75 años de edad). 
Por ello, con el fin de analizar de manera detallada dichas divergencias, se hace imprescindible proceder a un estudio individualizado de las distintas estructuras poblaciones de dichos municipios.

\subsubsection{ESTRUCTURA DE LA POBLACIÓN}

En el abastecimiento de agua la población surtida desempeña un papel fundamental, por ello, pasaremos a estudiar su compleja realidad analizando, en primer lugar, la "estructura de la población". La situación actual que presenta la distribución de la población es fruto de una evolución a lo largo de los años, y resulta de los efectos que sobre la estructura poblacional ejercen los movimientos naturales y migratorios.

La pirámide de edades nos ilustra sobre la historia demográfica de la población de los municipios llevados a estudio y sobre el comportamiento de los elementos básicos de su evolución: migraciones, fecundidad y mortalidad. La pirámide de población es una representación gráfica de la distribución de la población, en un instante determinado, atendiendo a la edad y el sexo. El análisis de dicha composición poblacional resulta de interés desde el punto de vista demográfico y será de utilidad para poder predecir su comportamiento futuro.

Figura 3. Estructura etaria de los municipios llevados a estudio (a).

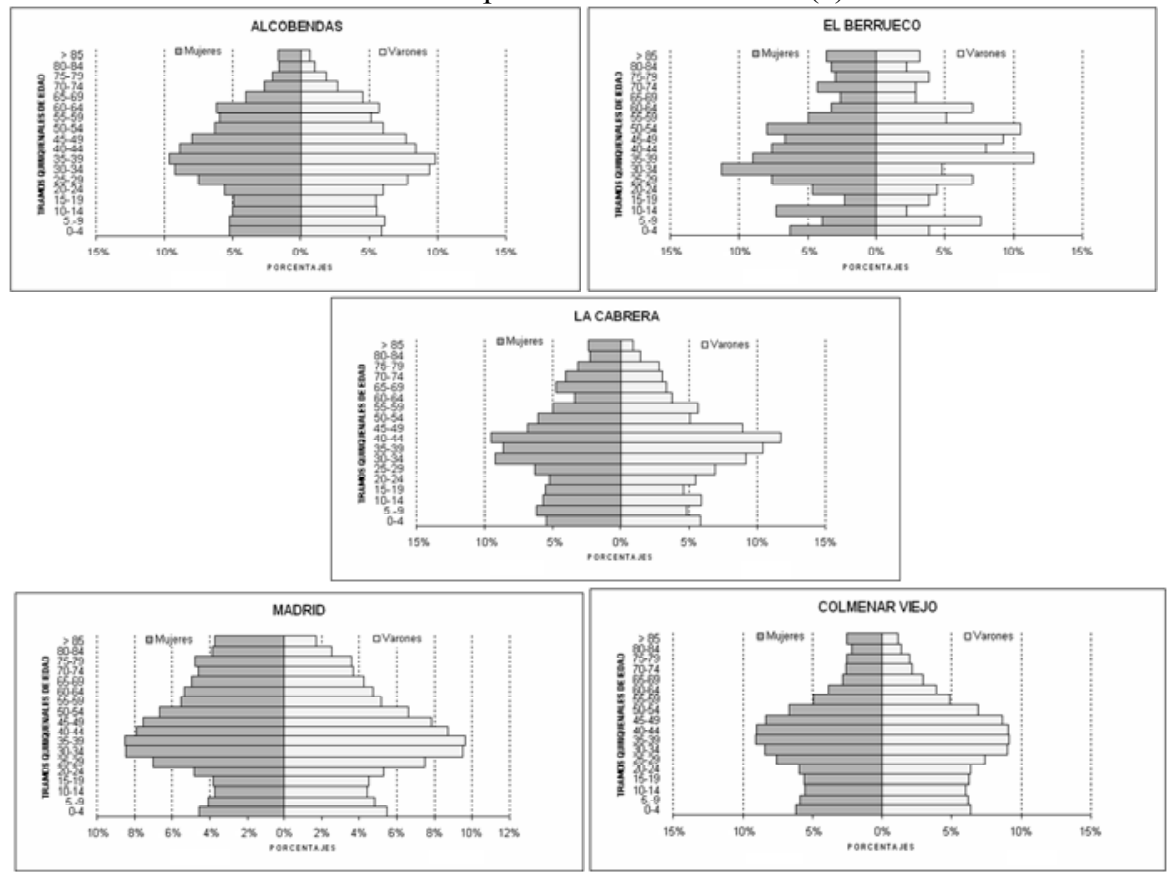

Fuente: Elaboración propia, a partir de los datos del Instituto de Estadística de la Comunidad de Madrid y del Instituto Nacional de Estadística. 
Si nos centramos en el análisis pormenorizado de cada uno de los municipios, podemos afirmar que se trata de poblaciones regresivas -fiel reflejo de ello lo encontramos en las distintas pirámides de población-, con independencia de las características intrínsecas de cada una de ellos, puesto que muestran claros signos de envejecimiento con niveles de natalidad y mortalidad reducidos, mientras que en edades intermedias (población en edad de trabajar) existen numerosos efectivos poblacionales.

Figura 3. Estructura etaria de los municipios llevados a estudio (b).

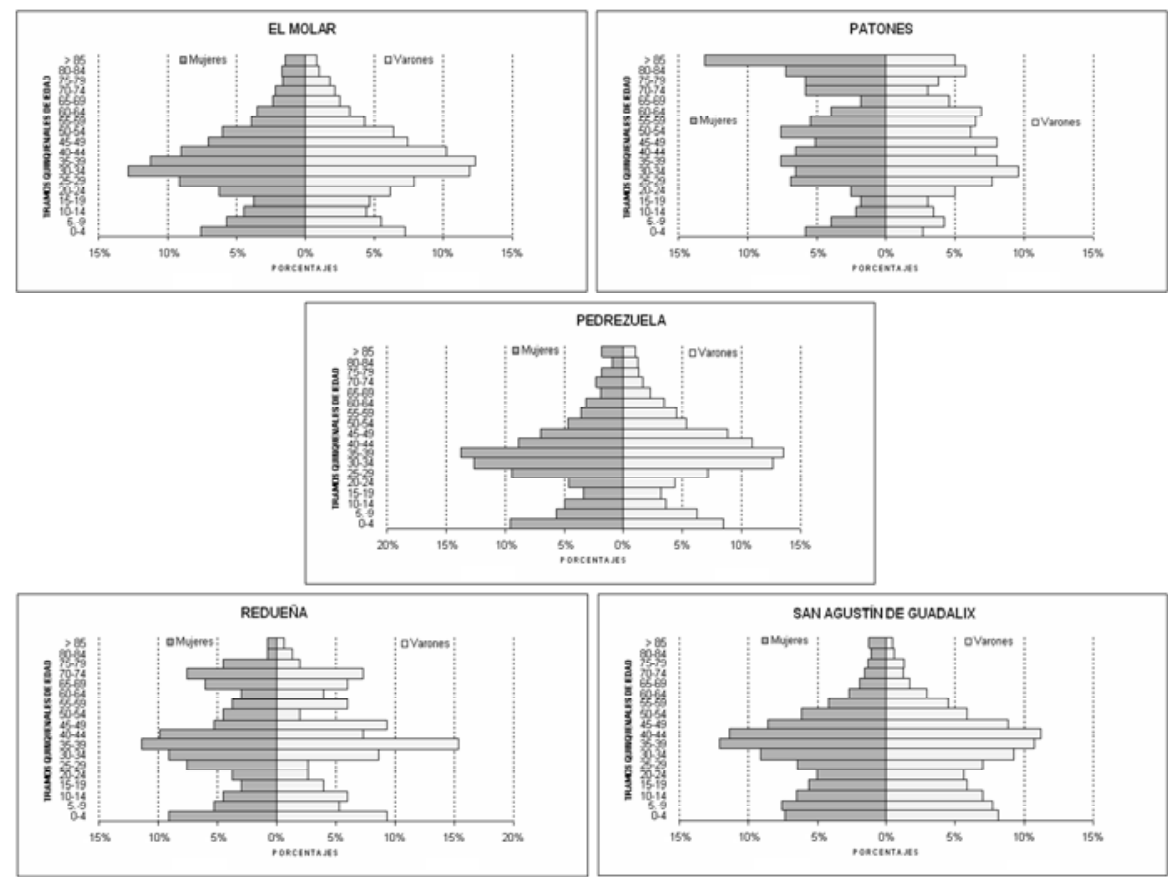

Fuente: Elaboración propia, a partir de los datos del Instituto de Estadística de la Comunidad de Madrid.

En el término municipal de Madrid, centro urbano de gran dinamismo, se aprecia como los procesos demográficos se acentúan con mayor intensidad, puesto que presenta una población elevada en edades comprendidas entre los 25 y los 55 años -la pirámide se estrecha tanto en la base como en la cúspide-, si bien la población menor de 15 años continúa siendo mayor que los habitantes con más de 70 años, ya que, a pesar del importante proceso de envejecimiento, el nivel de natalidad se ve reforzado por los movimientos migratorios y el propio crecimiento económico de la ciudad.

Por el contrario, municipios como Patones o Torremocha del Jarama se caracterizan por presentar una población muy envejecida, ya que la población mayor de 80 años supera de manera significativa a los efectivos poblacionales en edad de trabajar $\mathrm{y}$, sobre todo, a la población menor de 5 años; de ahí que podamos afirmar que son territorios que sufrirán problemas de relevo generacional (ver figura 3 (b)). 
Figura 3. Estructura etaria de los municipios llevados a estudio (c).
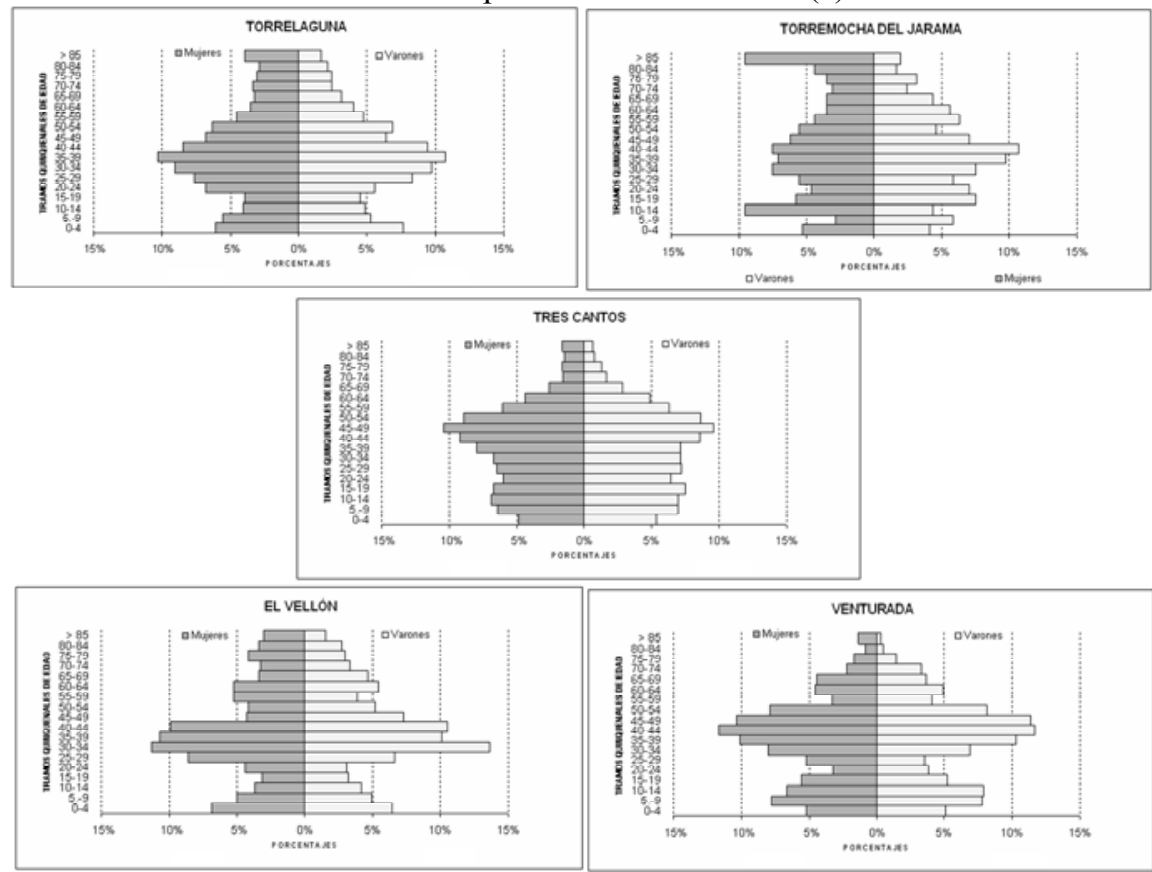

Fuente: Elaboración propia, a partir de los datos del Instituto de Estadística de la Comunidad de Madrid.

Por último, destacar el caso concreto de algunos municipios como El Berrueco, Redueña y el Vellón, en los que su estructura poblacional es consecuencia directa de los procesos migratorios acaecidos en los últimos años, ya que la afluencia de inmigrantes ha provocado fluctuaciones en la proporción de población, incrementando el número de habitantes en edad de trabajar que, a su vez, han favorecido el aumento tan destacado de su población menor de 15 años.

De hecho, muchos de los municipios, como El Molar, San Agustín de Guadalix o Venturada, son un claro de ejemplo de las mejoras en la calidad de vida de sus habitantes. En los últimos años, se ha incrementado la población residente en dichas áreas con el fin de disfrutar de las ventajas de vivir en un chalet, en áreas rurales o rururbanas, lo que ha aumentado, no solo la natalidad, sino los movimientos pendulares con motivo de trabajo ya que la población reside en estos municipios y trabaja en centros urbanos más dinámicos como Madrid, Tres Cantos o Alcobendas.

\subsubsection{EVOLUCIÓN DE LA POBLACIÓN}

Indudablemente, la evolución de los métodos extractivos de recursos hídricos, y, por ende, la construcción de las infraestructuras del Canal de Isabel II, amén de estar vinculados al propio progreso tecnológico, ha estado marcado por la creciente evolución demográfica; siendo esta, no solo un mero condicionante, sino un elemento 
determinado por la construcción y disposición de dichos Canales, que ha incidido positivamente en los procesos de urbanización que acompañan al crecimiento poblacional.

La imagen claramente discontinua y no sostenida que ofrece el crecimiento histórico de la población madrileña ha sido reforzada por las investigaciones de Ringrose (1969), Vinuesa Angulo (2004), en torno al consumo en Madrid de artículos de primera necesidad (Valenzuela, M., 1987), como es el recurso hídrico. Por ello, la evolución de la población municipal por los que transcurren los Canales a partir de 1857, fecha que abre los censos estadísticos modernos en España (un año antes de que se inauguraran las primeras infraestructuras del Canal de Isabel II -en 1858 entra en servicio el denominado Canal Bajo-).

Figura 4. Evolución de la población desde 1857 hasta la actualidad.
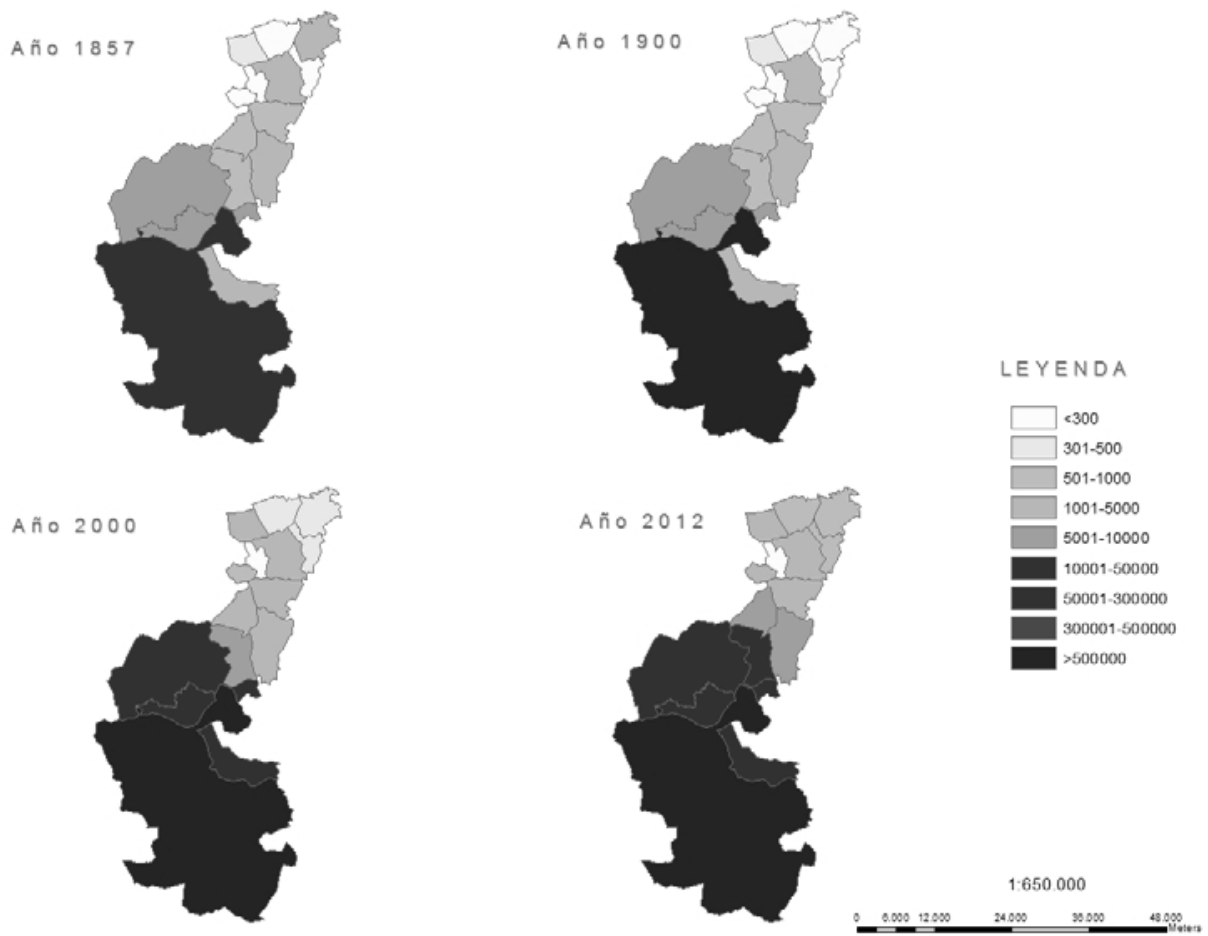

Fuente: Elaboración propia, a partir de los datos del Instituto de Estadística de la Comunidad de Madrid y del Instituto Nacional de Estadística.

La población de los municipios estudiados ha ido aumentando de manera progresiva (aunque no regular en el tiempo) desde 1857 hasta la actualidad. Cabe destacar que en el año 1857 la población del municipio de Madrid era de 298.638 habitantes, superaba el medio millón de habitantes a comienzos del siglo XX, se aproximaba a 
los tres millones en los albores del siglo XIX y los superaba en 2012, alcanzando la cifra de 3.233.527 de personas. (Ver figura 4).

De igual modo, en el municipio de Alcobendas residían 1.513 habitantes en el año 1857 reduciéndose en el año 1900 hasta los 1.347 habitantes, si bien su población se incremento de manera importante en el siglo XX hasta alcanzar las 89.612 personas en el año 2000 y superando los cien mil habitantes en 2012.

Lo mismo ha ocurrido en el resto de municipios estudiados, la población ha ido aumentando considerablemente en la actualidad en comparación con 1857, si bien, dichos niveles poblacionales tendieron a reducirse (de manera poco significativa) durante la segunda mitad del siglo XIX, provocando un proceso de transición demográfica importante durante todo el siglo XX.

En consonancia con lo anteriormente descrito, con frecuencia, las infraestructuras del Canal de Isabel II no se vieron culminadas hasta después de la Guerra Civil, como es el caso del Canal Alto. No obstante, las mejoras en las conducciones se especificaron a partir de las canalizaciones y las fórmulas de gestión introducidas entre $1850 \mathrm{y}$ 1900, lo que coadyuva al crecimiento continuado de la población de dichos municipios; no solo, por el propio proceso de construcción que favoreció la demanda de mano de obra, sino porque el acceso al recursos hídrico, al agua potable, a mejoras en el saneamiento y la higiene, incidieron positivamente en la calidad de vida de sus habitantes. La evolución de los servicios urbanos fue incrementándose paulatinamente, a tenor de la llegada del agua a estos municipios y del propio proceso demográfico que emanaba de aquellas construcciones hidráulicas.

Por otro lado, señalar que el crecimiento demográfico de municipios como Colmenar Viejo o Tres Cantos no ha sido tan espectacular como era de esperar, si lo comparamos con los municipios de Madrid o Alcobendas, ya que en 1857 tenían una población (sumando ambos municipios, ya que hasta 1986 formaban parte del mismo termino municipal) de 5.115 habitantes, mientras que en 2012 la población en Colmenar Viejo se había incrementado hasta alcanzar los 46.321 habitantes, y, en Tres Cantos ascendía a las 41.302 personas.

Por último, podemos destacar que tan solo el término municipal de Patones ha reducido su población desde 1857 hasta la actualidad, pasando de tener 1.234 habitantes a las 521 personas que residían en 2012 .

\subsubsection{TIPOS DE DINÁMICAS DEMOGRÁFICAS: EL MOVIMIENTO NATURAL DE LA POBLACIÓN}

El saldo natural o crecimiento vegetativo es el resultado de la relación entre los nacimientos y las defunciones de un lugar, en un periodo de tiempo determinado, dependiendo de él la dinámica demográfica cuando los movimientos migratorios son nulos (Nieto, J.A. y Egea, C., 2005). De ahí la importancia que cobra estudiar cada uno de los componentes del mismo. 
Figura 5. Crecimiento vegetativo de la zona de estudio.

\begin{tabular}{ccccc|c} 
AÑo 2012 & Nacimientos & Defunciones & Matrimonios & $\begin{array}{c}\text { Crecimiento } \\
\text { Vegetativo }\end{array}$ \\
Alcobendas & 1.119 & 495 & 398 & 624 \\
El Berrueco & 5 & 6 & 3 & -1 \\
La Cabrera & 27 & 22 & 13 & 5 \\
Colmenar Viejo & 547 & 268 & 204 & 279 \\
Madrid & 32.938 & 26.544 & 12.941 & 6.394 \\
El Molar & 133 & 34 & 28 & 99 \\
Patones & 1 & 10 & 3 & -10 \\
Pedrezuela & 101 & 19 & 28 & 82 \\
Redueña & 4 & 2 & 5 & 2 \\
San Agustín del & & & & 156 \\
Guadalix & 196 & 40 & 58 & 5 \\
Torrelaguna & 48 & 43 & 21 & 1 \\
Torremocha de & & & & 18 \\
Jarama & 8 & 7 & 6 & 211 \\
El Vellón & 27 & 9 & 11 & 12 \\
Venturada & 17 & 4 & 123 & \\
Tres Cantos & 381 & 170 & 12 &
\end{tabular}

Fuente: Elaboración propia, a partir de los datos del Instituto de Estadística de la Comunidad de Madrid.

Históricamente, puede afirmarse que la población madrileña ha pasado de un régimen demográfico primitivo (alta natalidad y alta mortalidad), caracterizado por el casi nulo crecimiento natural, a otro maduro (baja natalidad y mortalidad) de crecimiento muy reducido (Valenzuela, M., 1987). Si analizamos detalladamente los datos recogidos en la figura 11, observamos que el número de nacimientos en todos y cada uno de los municipios estudiados es relativamente baja, pues apenas supone el $1 \%$ de la población total -a excepción de Pedrezuela, que supera el 2\% y, en muchos casos es inferior al $0,9 \%$-. Por lo que, en la mayor parte de los municipios la natalidad se ha ido reduciendo progresivamente.

Respecto a la mortalidad, podemos afirmar que el número de defunciones es elevado, en comparación con el de nacimientos consecuencia del envejecimiento de la población. Destaca sobre todo los casos de El Berrueco y Patones que presentan un crecimiento vegetativo negativo, o Redueña y Torremocha del Jarama cuyo número de nacimientos excede solo en una persona al número de fallecidos.

De forma concreta, podemos afirmar que el susodicho envejecimiento demográfico viene definido por el aumento de la proporción de personas ancianas; la evolución de las defunciones es ascendente, en general, por el envejecimiento de la población, aunque también afecta personas jóvenes como consecuencia de cánceres, accidentes de tráfico, enfermedades pulmonares,... Por otro lado, señalar que la sobre representación de las mujeres está influida por la mortalidad diferencial intersexos y los procesos inmigratorios acaecidos en los últimos años (ver figura 6). 
El índice de envejecimiento es relativamente elevado en municipios como Madrid $(19,39 \%)$, Redueña $(18,90 \%)$, Patones $(28,21 \%)$ y Torremocha del Jarama $(20,87 \%)$, Si bien, estos altos índices de envejecimiento no se ven compensados con índices de juventud elevados (a excepción de Redueña), y, por ende, su razón de juventud también es relativamente baja. Todo ello favorece al envejecimiento progresivo de su población que, carente de un relevo generacional importante, incidiendo en el descenso de su población, el decrecimiento económico $y$, en cierta medida, la pérdida de calidad de vida.

Figura 6. Principales índices demográficos.

\begin{tabular}{cc|c|c|c}
$\begin{array}{c}\text { AÑO 2012 } \\
\text { Alcobendas }\end{array}$ & $\begin{array}{c}\text { Índice de } \\
\text { Juventud }\end{array}$ & $\begin{array}{c}\text { Índice de } \\
\text { Envejecimiento }\end{array}$ & $\begin{array}{c}\text { Razón de } \\
\text { Juventud }\end{array}$ & $\begin{array}{c}\text { Razón de } \\
\text { Progresividad }\end{array}$ \\
\hline El Berrueco & 16,59 & 12,20 & 135,97 & 95,80 \\
La Cabrera & 14,69 & 16,83 & 87,25 & 69,44 \\
Colmenar Viejo & 16,34 & 14,27 & 114,48 & 104,44 \\
Madrid & 18,06 & 11,43 & 158,06 & 102,45 \\
El Molar & 13,55 & 19,39 & 69,89 & 112,11 \\
Patones & 18,06 & 8,89 & 203,28 & 134,43 \\
Pedrezuela & 9,98 & 28,21 & 35,37 & 68,00 \\
Redueña & 19,82 & 7,95 & 249,37 & 135,74 \\
San Agustín del & 20,62 & 18,90 & 109,09 & 155,56 \\
Guadalix & 22,35 & 6,43 & 347,62 & 96,57 \\
Torrelaguna & 16,98 & 14,57 & 116,53 & 117,71 \\
Torremocha de & & & & \\
Jarama & 15,62 & 20,87 & 74,86 & 127,27 \\
El Vellón & 15,02 & 16,67 & 90,14 & 134,09 \\
Venturada & 19,82 & 10,02 & 197,89 & 60,96 \\
Tres Cantos & 18,29 & 8,63 & 211,87 & 76,55 \\
\hline
\end{tabular}

Fuente: Elaboración propia, a partir de los datos del Instituto de Estadística de la Comunidad de Madrid y del Instituto Nacional de Estadística.

Mientras que otros como Tres Cantos, Venturada, El Molar o San Agustín de Guadalix el índice de envejecimiento es igual o inferior al 10\%, en contraposición de sus índices de juventud y la razón de juventud, que son de los más elevados de nuestra área de estudio, como consecuencia directa de lo anteriormente expuesto.

Por otro lado, afirmar que la tasa de crecimiento vegetativo, se mantiene en la Comunidad de Madrid y, concretamente, en los municipios estudiados, a unos niveles muy bajos en las tres primeras décadas del siglo XX como consecuencia directa de los periodos bélicos o por procesos epidémicos (fundamentalmente, gripe), viéndose modificada, sobre todo, a partir de los años " 60 " y " 70 " del siglo pasado. Actualmente, $\tan$ solo El Berrueco y Patones presentan una tasa de crecimiento vegetativo negativo, si bien, municipios como La Cabrera, Madrid o Torremocha del Jarama presen- 
tan una tasa que apenas supera el $1 \%$, lo que nos indica la compleja realidad demográfica de estos municipios (ver figura 7).

Figura 7. Principales tasas del movimiento natural de la población.

\begin{tabular}{|c|c|c|c|c|c|}
\hline AÑO 2012 & $\begin{array}{l}\text { Tasa Bruta de } \\
\text { Natalidad }\end{array}$ & $\begin{array}{l}\text { Tasa General de } \\
\text { Fecundidad }\end{array}$ & $\begin{array}{l}\text { Tasa Bruta de } \\
\text { Mortalidad }\end{array}$ & $\begin{array}{c}\text { Tasa de } \\
\text { Crecimiento } \\
\text { Vegetativo }\end{array}$ & $\begin{array}{l}\text { Tasa de } \\
\text { Feminidad }\end{array}$ \\
\hline Alcobendas & 10,08 & 18,82 & 4,46 & 5,62 & 1,07 \\
\hline EI Berrueco & 8,25 & 16,72 & 9,90 & $-1,65$ & 0,91 \\
\hline La Cabrera & 10,53 & 19,42 & 8,58 & 1,95 & 0,97 \\
\hline Colmenar Viejo & 11,81 & 21,73 & 5,79 & 6,02 & 1,02 \\
\hline Madrid & 10,19 & 20,52 & 8,21 & 1,98 & 1,14 \\
\hline El Molar & 16,17 & 27,59 & 4,13 & 12,04 & 0,96 \\
\hline Patones & 1,92 & 4,52 & 19,19 & $-17,27$ & 1,08 \\
\hline Pedrezuela & 20,12 & 33,81 & 3,78 & 16,33 & 0,95 \\
\hline Redueña & 13,75 & 27,03 & 6,87 & 6,87 & 0,87 \\
\hline $\begin{array}{l}\text { San Agustín del } \\
\text { Guadalix }\end{array}$ & 15,35 & 26,72 & 3,13 & 12,22 & 1,01 \\
\hline Torrelaguna & 9,88 & 18,64 & 8,85 & 1,03 & 0,95 \\
\hline $\begin{array}{l}\text { Torremocha de } \\
\text { Jarama }\end{array}$ & 9,12 & 19,51 & 7,98 & 1,14 & 1,11 \\
\hline El Vellón & 15,31 & 28,75 & 5,10 & 10,20 & 0,93 \\
\hline Venturada & 8,96 & 17,03 & 2,11 & 6,85 & 0,93 \\
\hline Tres Cantos & 9,22 & 17,52 & 4,12 & 5,11 & 1,06 \\
\hline
\end{tabular}

Fuente: Elaboración propia, a partir de los datos del Instituto de Estadística de la Comunidad de Madrid.

En cuanto a la tasa general de fecundidad, definida como el número de nacidos vivos por 1.000 de mujeres con edades que oscilan entre los 15 y 49 años observamos que ha sufrido, en el último cuarto de siglo, cambios propios de las sociedades más desarrolladas. Entre estos cambios destacan el descenso de la fecundidad -si bien, parecen iniciar una ligera recuperación en los últimos años-, procesos de envejecimiento progresivo o la concentración de los nacimientos en determinados grupos de edad.

\subsubsection{LA MOVILIDAD ESPACIAL DE LA POBLACIÓN}

En los últimos años, España ha dejado de ser un país origen de migración pasando a recibir importantes contingentes de población extranjeros. De hecho, la movilidad de la población es un factor asociado al desarrollo de las regiones. Como afirma el profesor Vinuesa Angulo (2004), Madrid ha sido tradicionalmente considerada como una ciudad que aglutina a una población de orígenes muy diversos. El estudio de la dinámica demográfica permite corroborar unas altas tasas de aloctonía, que en las últimas décadas se han ido extendiendo a toda la Comunidad. Mientras el 91,1\% de la población de España había nacido en el mismo municipio de residencia o en otro de la misma provincia, en Madrid solo el 57,6\% se encontraba en esta situación. Asimismo, el 41,8\% de la población residente en Madrid en 1900 había nacido en otra provincia, 
frente al 8,6\% observado en España (Cuadernos Fundación BBVA, 2008) (ver figura $8)$.

Figura 8. Porcentaje de población española y extranjera por municipios (a 1 de enero de 2012).

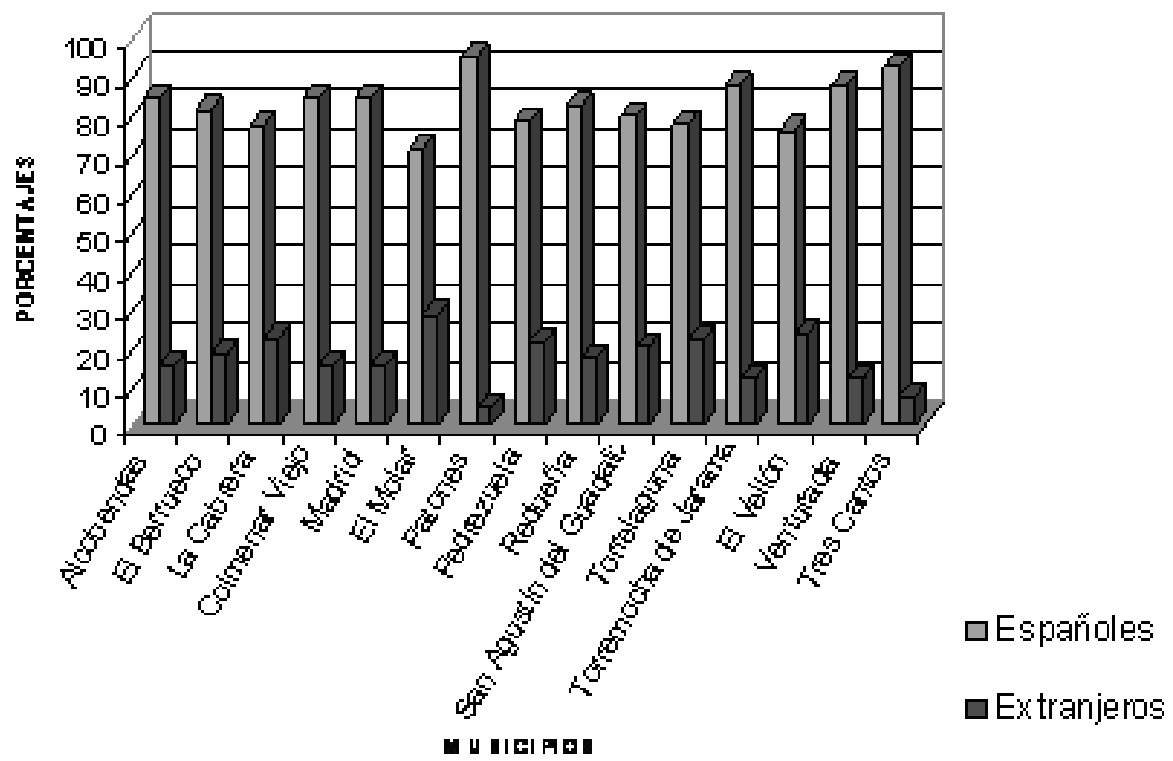

Fuente: Elaboración propia, a partir de los datos del Instituto de Estadística de la Comunidad de Madrid y del Instituto Nacional de Estadística.

Así pues, puede afirmarse que la población madrileña es en buena medida consecuencia de la "explosión urbana" que se alimentó de fuentes migratorias interprovinciales, vinculados a los procesos de industrialización y de urbanización del conjunto de España, en los que Madrid, por distintos motivos, se convirtió en el principal centro de concentración (Vinuesa Angulo, J, 2004). De hecho, la bonanza económica de España en los últimos años ha favorecido la atracción de población de otros países, convirtiéndose en un "país" de acogida (Cuadernos Fundación BBVA, 2008).

El porcentaje de población extranjera es sustancialmente importante en algunos municipios como La Cabrera, El Molar, Pedrezuela, San Agustín de Guadalix, Torrelaguna y El Vellón, en los que más del $20 \%$ de su población no es española. En contraposición, Patones y Tres Cantos menos del $8 \%$ de su población es extranjera (sin lugar a dudas estos son fenómenos a tener en cuenta a la hora de valorar el abastecimiento de agua a estas localidades). 
Figura 9. Tasa de migración y procedencia de los inmigrantes (año 2010).

\begin{tabular}{|c|c|c|c|c|}
\hline AÑO 2010 & $\begin{array}{l}\text { Tasa de } \\
\text { migración }\end{array}$ & $\begin{array}{c}\text { Destino y } \\
\text { procedencia la C. } \\
\text { Madrid }\end{array}$ & Extranjeros & $\begin{array}{c}\text { Procedente de } \\
\text { otras CC.AA. }\end{array}$ \\
\hline Alcobendas & $-7,26$ & 4654 & 1926 & 1322 \\
\hline El Berrueco & 4,92 & 44 & 0 & 11 \\
\hline La Cabrera & $-1,59$ & 91 & 24 & 18 \\
\hline Colmenar Viejo & 17,42 & 494 & 625 & 1589 \\
\hline Madrid & $-4,79$ & 51.475 & 40.809 & 36.380 \\
\hline El Molar & 33,42 & 135 & 532 & 134 \\
\hline Patones & 91,26 & 1 & 67 & 4 \\
\hline Pedrezuela & 26,44 & 59 & 505 & 86 \\
\hline Redueña & 3,57 & 0 & 36 & 3 \\
\hline $\begin{array}{l}\text { San Agustín del } \\
\text { Guadalix }\end{array}$ & 35,05 & 148 & 733 & 176 \\
\hline Torrelaguna & $-7,52$ & 233 & 56 & 87 \\
\hline $\begin{array}{l}\text { Torremocha de } \\
\text { Jarama }\end{array}$ & 84,54 & 118 & 5 & 19 \\
\hline Tres Cantos & $-5,16$ & 1038 & 316 & 456 \\
\hline El Vellón & 38,71 & 31 & 161 & 44 \\
\hline Venturada & 66,07 & 26 & 206 & 12 \\
\hline
\end{tabular}

Fuente: Elaboración propia, a partir de los datos del Instituto de Estadística de la Comunidad de Madrid

Las tendencias demográficas actuales muestran que la migración a Madrid anterior a 1960 presentaba una marcada preferencia por el municipio de Madrid; es lógico pensar que los emigrantes elegirían su lugar de residencia en la zona de la aglomeración más próxima a su lugar de origen. Mientras que en el resto de la provincia se daba una tendencia a concentrarse a lo largo de las rutas de acceso a Madrid provenientes de sus respectivas regiones, de origen en el caso de los inmigrantes de bajo estatus social (peones y trabajadores de la construcción).

En la actualidad, la dinámica demográfica ha evolucionado notablemente (figura 15), el municipio de Madrid ha dejado de ser un centro de atracción de población, ya que su tasa de migración negativa nos muestra que los niveles de emigración superan a los de inmigración; lo mismo sucede en municipios como Alcobendas, La Cabrera, Torrelaguna y Tres Cantos. Por el contrario, municipios como Patones, Torremocha del Jarama y Venturada presentan altísimas tasas de migración (superiores al 50\%).

Sin lugar a dudas se da, de esta manera, una relación causa efecto entre los mismos servicios unidos al agua, y los propios movimientos migratorios. De hecho, se plasma - directa o indirectamente- en los cambios demográficos que han acontecido en los últimos años, sobre todo, en términos de movilidad espacial. La mejora en la calidad de vida, las expectativas laborales, el crecimiento y desarrollo económico, han favorecido un cambio de modelo residencial, que gracias a la gestión y abastecimiento de 
agua llevado a cabo por el Canal de Isabel II, ha permitido generar una nueva demanda residencial en zonas rururbanas alejadas del centro urbano de Madrid.

\section{LA ESTRUCTURA PRODUCTIVA, BASE DE LAS RELACIONES CAUSA/EFECTO}

Madrid constituye la mayor aglomeración urbana del país, que adopta la forma de "ciudad región", esto es, una gran ciudad formada por un aglomerado urbano central, a modo de área metropolitana, una ciudad dispersa, de más difícil delimitación, y un medio rururbano complejo. En el territorio de Madrid los procesos de urbanización han generado un espacio económico y social igualmente contrastado que fisiográficamente variado, de manera que uno y otro componente de heterogeneidad se traducen en los consumos de agua (Sotelo Navalpotro, J.A. et alii, 2011).

Figura 10. Producto Interior Bruto de los municipios.

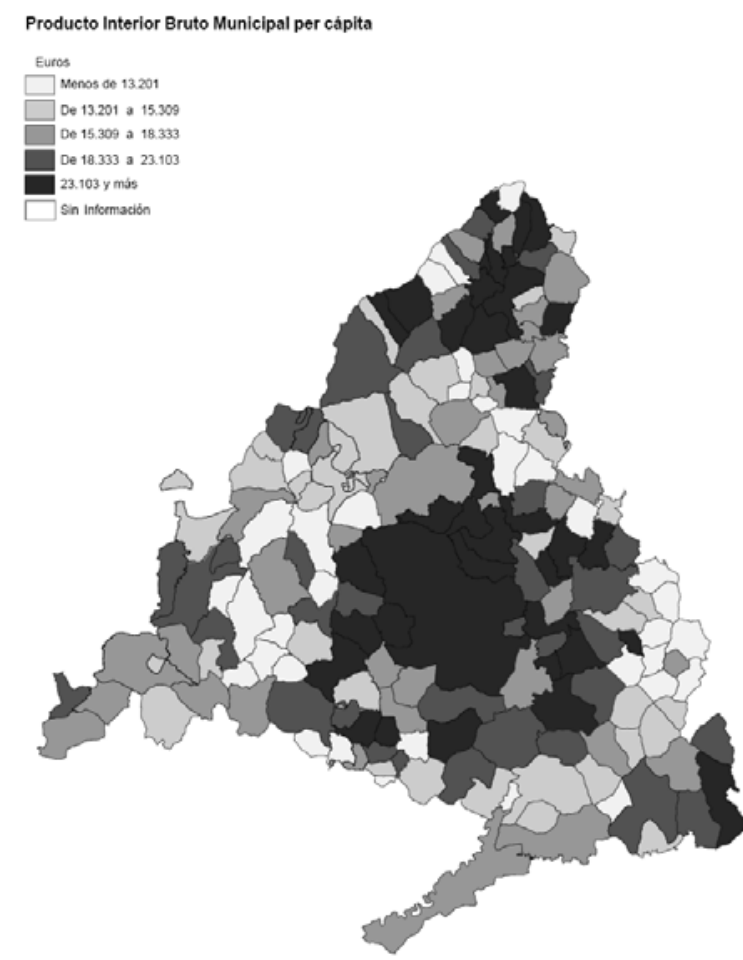

Fuente: Instituto de Estadística de la Comunidad de Madrid

\begin{tabular}{cr|} 
& PIB (2009) \\
\hline Alcobendas & 6.409 .446 \\
\hline El Berrueco & 10.410 \\
\hline La Cabrera & 45.444 \\
Colmenar Viejo & 717.719 \\
Madrid & 124.649 .726 \\
El Molar & 93.334 \\
Patones & 9.001 \\
Pedrezuela & 64.125 \\
Redueña & 4.886 \\
San Agustín del & \\
Guadalix & 298.185 \\
Torrelaguna & 176.639 \\
Torremocha de & \\
Jarama & 14.644 \\
Tres Cantos & 2.793 .777 \\
El Vellón & 20.609 \\
Venturada & 20.635
\end{tabular}

A tenor de los datos recogidos se colige que los municipios con mayor equipamiento infraestructural, como Madrid, Alcobendas y Tres Cantos, presentan niveles muy superiores de Producto Interior Bruto. Sus aportaciones se deben, fundamental- 
mente, al gran dinamismo que emana de dichas áreas urbanas; la diversificación en las actividades productivas, centradas principalmente en los sectores terciario y cuaternario, favorecen la atracción de mano de obra de otros municipios próximos -lo que, en muchos casos, repercute de manera negativa sobre la producción, productividad y renta de los mismos, sobre todo de aquellos que se caracterizan por ser "ciudades dormitorio" o "segundas residencias"-. Por el contrario, municipios como El Berrueco, Patones o Redueña presentan aportaciones relativamente bajas en términos de Producto Interior Bruto, puesto que su actividad se fundamenta en el sector primario -si bien, se dan actividades propias de otros sectores económicos-, su población está relativamente envejecida y se caracterizan por ser municipios donde predominan las segundas residencias, lo que influye directa o indirectamente, en su estructura poblacional, de manera general, y productiva, en particular (ver figura 20).

Por todo ello, se confirma de forma general la proposición de que un mejor equipamiento de infraestructuras incrementa la productividad de la inversión privada, en la medida en que rebaja los costes privados. Una región bien equipada con infraestructuras tendrá, por consiguiente, una ventaja comparativa con respecto a otra peor equipada. Ello redundará en un PIB $_{\text {per cápita }}$ regional más alto y/o un mayor nivel de empleo. La primera proposición que se desprende del enfoque aquí presentado es la de que la productividad, la renta y el empleo regional son funciones crecientes del equipamiento infraestructural de la región (Biehl, 1988), desempeñando un papel fundamental las infraestructuras de abastecimiento de agua del Canal de Isabel II.

Figura 11. Número total de activos por grupos de edad.

\begin{tabular}{|c|c|c|c|c|c|c|}
\hline Activos (2012) & $\begin{array}{c}\text { De } 16 \text { a } 19 \\
\text { años }\end{array}$ & $\begin{array}{c}\text { De } 20 \text { a } 24 \\
\text { años }\end{array}$ & $\begin{array}{c}\text { De } 25 \text { a } 34 \\
\text { años }\end{array}$ & $\begin{array}{c}\text { De } 35 \text { a } 44 \\
\text { años }\end{array}$ & $\begin{array}{c}\text { De } 45 \text { a } 54 \\
\text { años }\end{array}$ & $\begin{array}{c}\text { De } 55 \text { años y } \\
\text { más }\end{array}$ \\
\hline Alcobendas & 2863 & 3187 & 9314 & 10082 & 7685 & 8702 \\
\hline El Berrueco & 10 & 14 & 47 & 56 & 53 & 40 \\
\hline La Cabrera & 65 & 69 & 201 & 257 & 172 & 165 \\
\hline Colmenar Viejo & 1350 & 1400 & 3694 & 4133 & 3482 & 2666 \\
\hline Madrid & 67830 & 82508 & 264755 & 282592 & 233589 & 245720 \\
\hline El Molar & 168 & 248 & 832 & 854 & 537 & 398 \\
\hline Patones & 7 & 10 & 41 & 39 & 36 & 39 \\
\hline Pedrezuela & 77 & 106 & 488 & 551 & 304 & 221 \\
\hline Redueña & 5 & 5 & 20 & 31 & 15 & 21 \\
\hline $\begin{array}{l}\text { San Agustín del } \\
\text { Guadalix }\end{array}$ & 357 & 332 & 989 & 1411 & 916 & 562 \\
\hline Torrelaguna & 104 & 152 & 428 & 480 & 326 & 288 \\
\hline $\begin{array}{l}\text { Torremocha de } \\
\text { Jarama }\end{array}$ & 29 & 25 & 57 & 75 & 51 & 60 \\
\hline Tres Cantos & 1457 & 1276 & 2822 & 3385 & 3863 & 2785 \\
\hline El Vellón & 28 & 33 & 177 & 182 & 93 & 123 \\
\hline Venturada & 50 & 33 & 110 & 204 & 176 & 116 \\
\hline
\end{tabular}

Fuente: Elaboración propia, a partir de los datos del Instituto de Estadística de la Comunidad de Madrid.

Por otro lado, si nos centramos en el mercado de trabajo, podemos observar - con independencia del municipio en que nos encontremos- como las mayores tasas de actividad se aprecian entre los efectivos poblacionales mayores de 25 años, como consecuencia de la masiva afluencia de inmigrantes -nacionales, internacionales,...- 
en edad laboral, y del gran dinamismo de estas áreas, fruto del desarrollo económico. Si bien, el número total de activos se reduce de manera significativa entre los trabajadores activos entre 45 y 54 años; Todo ello como consecuencia directa de las condiciones estructurales de la población residente en nuestra zona de estudio.

De igual modo, destacar que los desequilibrios población vs. empleo emanan de la fuerte segregación espacial existente entre centros de empleo y áreas residenciales (Valenzuela, M., 1987); por lo que las mejoras en el equipamiento infraestructural de las conducciones del Canal de Isabel II, han favorecido el desarrollo de un mayor dinamismo económico de los municipios por los que discurren y a los que abastece, coadyuvando, no sólo el crecimiento de la población, sino que, también, mejorando las condiciones de empleo y, por ende, de calidad de vida, de sus habitantes, tal y como se deduce de los datos de empleo, renta y producción.

Figura 12. Número total de ocupados por grupos de edad.

\begin{tabular}{|c|c|c|c|c|c|c|}
\hline Ocupados (2012) & $\begin{array}{c}\text { De } 16 \text { a } 19 \\
\text { años }\end{array}$ & $\begin{array}{c}\text { De } 20 \text { a } 24 \\
\text { años }\end{array}$ & $\begin{array}{c}\text { De } 25 \text { a } 34 \\
\text { años }\end{array}$ & $\begin{array}{c}\text { De } 35 \text { a } 44 \\
\text { años }\end{array}$ & $\begin{array}{c}\text { De } 45 \text { a } 54 \\
\text { años }\end{array}$ & $\begin{array}{c}\text { De } 55 \text { años y } \\
\text { más }\end{array}$ \\
\hline Alcobendas & 1064 & 2015 & 7631 & 8567 & 6729 & 7706 \\
\hline El Berrueco & 4 & 9 & 39 & 47 & 46 & 35 \\
\hline La Cabrera & 24 & 43 & 165 & 218 & 150 & 146 \\
\hline Colmenar Viejo & 502 & 885 & 3026 & 3512 & 3049 & 2361 \\
\hline Madrid & 25205 & 52176 & 216921 & 240132 & 204559 & 217616 \\
\hline El Molar & 62 & 157 & 681 & 725 & 470 & 352 \\
\hline Patones & 2 & 6 & 34 & 33 & 32 & 35 \\
\hline Pedrezuela & 28 & 67 & 399 & 468 & 266 & 195 \\
\hline Redueña & 2 & 3 & 16 & 26 & 13 & 18 \\
\hline $\begin{array}{c}\text { San Agustín del } \\
\text { Guadalix }\end{array}$ & 133 & 210 & 810 & 1199 & 802 & 498 \\
\hline Torrelaguna & 39 & 96 & 351 & 408 & 285 & 255 \\
\hline $\begin{array}{l}\text { Torremocha de } \\
\text { Jarama }\end{array}$ & 11 & 16 & 47 & 64 & 44 & 53 \\
\hline Tres Cantos & 541 & 807 & 2312 & 2876 & 3383 & 2466 \\
\hline EI Vellón & 10 & 21 & 145 & 154 & 81 & 108 \\
\hline Venturada & 19 & 21 & 90 & 173 & 154 & 103 \\
\hline
\end{tabular}

Fuente: Elaboración propia, a partir de los datos del Instituto de Estadística de la Comunidad de Madrid

De igual modo, al analizar la estructura ocupacional, se hace imprescindible estudiar los niveles de paro, puesto que es un "fenómeno económico y social que presenta una problemática muy compleja, cuya incidencia va en ascenso a lo largo de los últimos años" (Valenzuela, M., 1987); achacable, de manera directa o indirecta, a la crisis económica y al proceso de recesión al que se ve sometida la economía española, en general, y madrileña, en particular. 
Figura 13. Número total de parados por grupos de edad.

\begin{tabular}{|c|c|c|c|c|c|c|}
\hline Parados (2012) & $\begin{array}{c}\text { De } 16 \text { a } 19 \\
\text { años }\end{array}$ & $\begin{array}{c}\text { De } 20 \text { a } 24 \\
\text { años }\end{array}$ & $\begin{array}{c}\text { De } 25 \text { a } 34 \\
\text { años }\end{array}$ & $\begin{array}{c}\text { De } 35 \text { a } 44 \\
\text { años }\end{array}$ & $\begin{array}{c}\text { De } 45 \text { a } 54 \\
\text { años }\end{array}$ & $\begin{array}{c}\text { De } 55 \text { años y } \\
\text { más }\end{array}$ \\
\hline Alcobendas & 1802 & 1171 & 1683 & 1515 & 955 & 994 \\
\hline El Berrueco & 6 & 5 & 8 & 8 & 7 & 5 \\
\hline La Cabrera & 41 & 25 & 36 & 39 & 21 & 19 \\
\hline Colmenar Viejo & 850 & 514 & 667 & 621 & 433 & 305 \\
\hline Madrid & 42705 & 30332 & 47834 & 42460 & 29030 & 28076 \\
\hline El Molar & 106 & 91 & 150 & 128 & 67 & 45 \\
\hline Patones & 4 & 4 & 7 & 6 & 4 & 4 \\
\hline Pedrezuela & 48 & 39 & 88 & 83 & 38 & 25 \\
\hline Redueña & 3 & 2 & 4 & 5 & 2 & 2 \\
\hline $\begin{array}{l}\text { San Agustín del } \\
\text { Guadalix }\end{array}$ & 225 & 122 & 179 & 212 & 114 & 64 \\
\hline Torrelaguna & 65 & 56 & 77 & 72 & 41 & 33 \\
\hline $\begin{array}{l}\text { Torremocha de } \\
\text { Jarama }\end{array}$ & 18 & 9 & 10 & 11 & 6 & 7 \\
\hline Tres Cantos & 917 & 469 & 510 & 509 & 480 & 318 \\
\hline El Vellón & 18 & 12 & 32 & 27 & 12 & 14 \\
\hline Venturada & 31 & 12 & 20 & 31 & 22 & 13 \\
\hline
\end{tabular}

Fuente: Elaboración propia, a partir de los datos del Instituto de Estadística de la Comunidad de Madrid

Indudablemente, a tenor de los datos recogidos en la figura 13, se aprecia como el problema del desempleo se distribuye de manera desigual entre los distintos municipios llevados a estudio, como consecuencia directa de los niveles de población que residen en ellos y del dinamismo económico que emana de dichas regiones. Sin embargo, destacan sobre los demás los términos municipales de Madrid, Alcobendas y Tres Cantos, que presentan niveles elevados de paro -si comparamos el número total de parados con el de activos-. Si bien, una característica propia de la mayor parte de los municipios es el paro juvenil (jóvenes menores de 25 años), consecuencia, en muchos casos, a que estos jóvenes son estudiantes y, algunos, tienen o buscan empleos temporales -amén de por las actuales circunstancias económicas del país.

Sin lugar a dudas, las mejores dotaciones en infraestructuras pueden favorecer la lucha contra el desempleo. De hecho, cabe destacar que las infraestructuras son, para algunos expertos, como el profesor Biehl - que utiliza el término infraestructura para designar la parte de capital global de una economía que posee eminentemente un carácter público-, un factor determinante o limitador del crecimiento económico, puesto que no viene dada por las transacciones privadas que se producen en el propio proceso de crecimiento -un supuesto básico del enfoque del potencial de desarrollo regional es que el coste de sustitución es mayor cuanto más público es el recurso-. Todo ello se traduce en el crecimiento económico de áreas más deprimidas, repercutiendo de manera directa sobre los niveles de renta disponible de regiones como Patones, La Cabrera, Toremocha del Jarama o Tres Cantos, en los que se han incrementado de manera considerable en los últimos años; en contraposición encontramos municipios como Torrelaguna, El Vellón o Pedrezuela cuya renta disponible apenas vario entre los años 2005 y 2010 (ver figura 14): 
Figura 14. Variación del nivel de Renta Disponible.

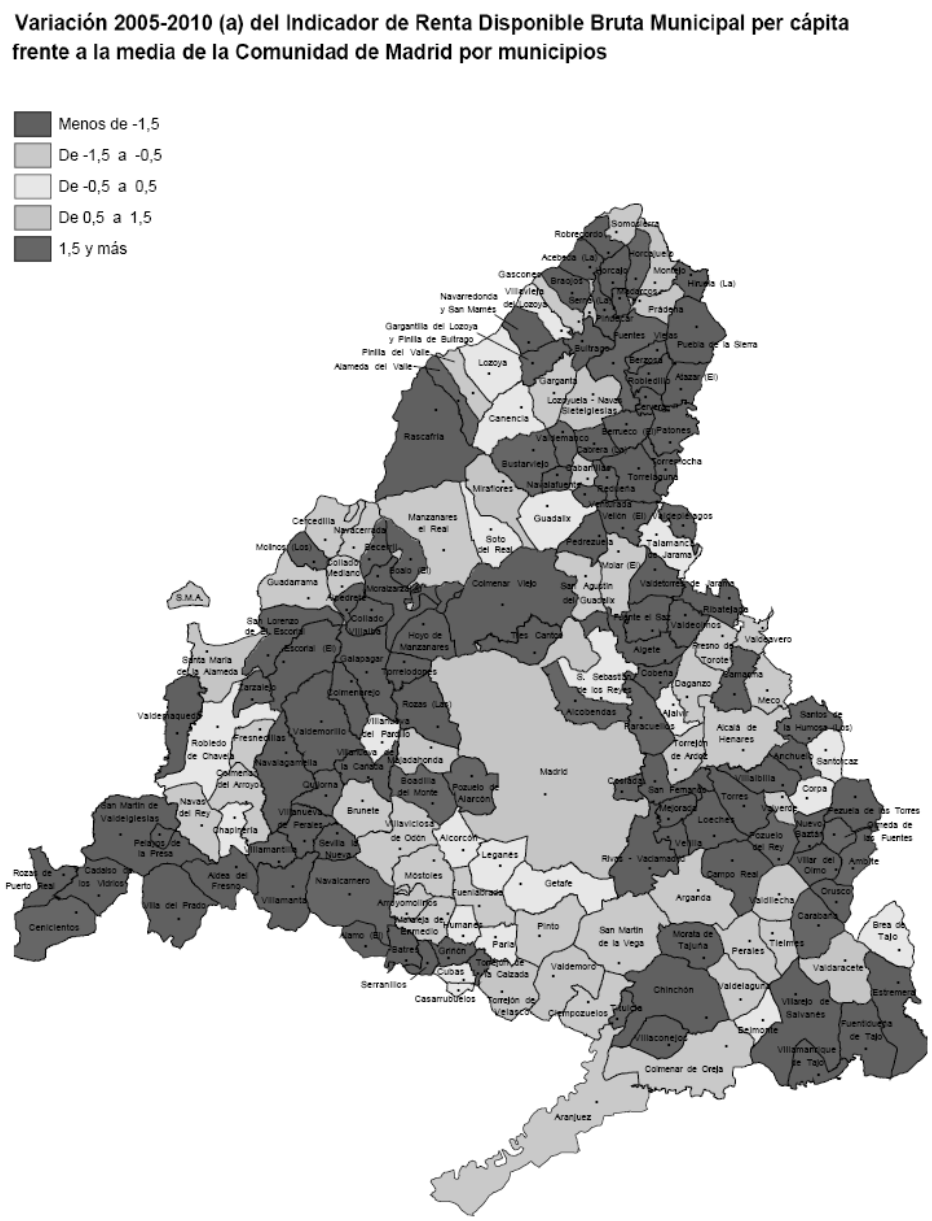

Fuente: Instituto de Estadística de la Comunidad de Madrid

\section{A MODO DE CONCLUSIONES}

A lo largo de los parágrafos anteriores se pone de manifiesto que las diferencias geográficas, en términos de la economía global, no plantean etapas en el desarrollo económico sino líneas de la nueva jerarquía global de producción. Grandes países con variadas economías (tales como la India o el Brasil) pueden sostener simultáneamente todos los niveles de los procesos productivos: producción de servicios basados en la información, producción industrial moderna de bienes, artesanía tradicional, agricultura y producción minera. No se trata de una progresión históricamente ordenada entre estas formas sino que más bien todas ellas se mezclan y coexisten dentro de las 
redes del mercado mundial y bajo la dominación de la producción informatizada de servicios.

El modelo industrial fordista que acompañó al proceso de modernización, provocó la intensa agregación de fuerzas productivas y de masas de fuerza de trabajo que tenía que "emigrar" hacia centros que se tornaron ciudades-fábricas. La eficiencia de la producción industrial masiva dependía de la concentración y proximidad de elementos para crear sitios fabriles y facilitar el transporte y la comunicación. En los procesos productivos, la comunicación y el control pueden ser eficientemente ejercidos a distancia y en algunos casos los productos inmateriales pueden ser transportados a través del mundo con mínimos gastos y retrasos. Sin embargo, tal como lo analizaremos más adelante, las principales áreas metropolitanas siguen concentrado (incluso cada vez más) grandes proporciones de población y actividades productivas.

Así, pues, tras lo anteriormente expuesto podemos llegar a distintas conclusiones; a saber:

La primera es que en el abastecimiento de agua la población surtida desempeña un papel fundamental, por lo que es de notable interés analizar y valorar la "estructura de la población" de nuestra zona de estudio, desempeñando un papel fundamental la situación que presenta la distribución de la población, fruto de una evolución a lo largo de los años, y resultado de los efectos que sobre la estructura poblacional ejercen los movimientos naturales y migratorios. Llama la atención que la mayor parte de los municipios estudiados muestran poblaciones que podríamos calificar de regresivas con claros síntomas de envejecimiento.

La segunda conclusión es que existe una clara correlación entre la mejora en las infraestructuras de abastecimiento de agua, y las tendencias demográficas actuales. Se ha generado una distribución de la población más coherente; de hecho, si los movimientos inmigratorios hacia la provincia, mostraban una clara preferencia de la migración a Madrid antes de los años sesenta del pasado siglo, a lo largo de las décadas posteriores la mejora de las infraestructuras coadyuvó a que estas preferencias se diversificaran, llegando al resto de municipios estudiados.

La tercera conclusión nos muestra que los municipios con mayor equipamiento infraestructural (Madrid,...) presentan niveles muy superiores de Producto Interior Bruto, como consecuencia del notable dinamismo que generan. Por el contrario, otros municipios $(\mathrm{El}$ Berrueco,...) presentan aportaciones relativamente bajas en términos de Producto Interior Bruto, puesto que su actividad se fundamenta en el sector primario su población está muy envejecida, y z más se relacionan con las segundas residencias, lo que influye directa o indirectamente, en su estructura poblacional y productiva.

En definitiva, en nuestra investigación se pone de manifiesto como el ciclo integral del agua en la ciudad sostenible, nos induce a entender que el desarrollo de la sociedad del futuro y entender que la calidad del medio natural es un reflejo de nuestra futura calidad de vida. En este sentido, el diagnostico del ciclo del agua de la ciudad, se refiere al origen del mismo en la ciudad, su uso y consumo por parte de la población y su posterior devolución al medio natural (Sotelo Navalpotro, J.A. et alii, 2011). 


\section{BIBLIOGRAFÍA}

ARENILLAS PARRA, M. (2000). Madrid y El Agua, "Historia del abastecimiento y usos del agua en la Villa de Madrid“, Macías José María-Segura, Cristina (coord.), Madrid, 185-190.

AA.VV. (1987). La naturaleza de Madrid. Comunidad de Madrid. Consejería de Agricultura y Ganadería.

AA.VV. (2008). Atlas de medioambiente de la Comunidad de Madrid. Comunidad de Madrid. Consejería de Medio Ambiente y Ordenación del Territorio.

CHARRAZA, A. (2011). Atlas climático ibérico. Ed. Ministerio de Medio Ambiente y Medio Rural y Marino, $79 \mathrm{pp}$.

FUNDACIÓN BBVA (2008). Cuadernos Fundación BBVA: Población. Madrid. INSTITUTO NACIONAL DE ESTADÍSTICA, INE (2013).

INSTITUTO DE ESTADÍSTICA DE LA COMUNIDAD DE MADRID (2013).

NIETO CALMAESTRA, J.A. y Egea Jiménez, C. (2005). La dinámica demográfica en Andalucía en el último cuarto del siglo XX. Cuadernos Geográficos, $\mathrm{n}^{\circ} 36$, pp. 125-151

RAFO, Juan y RIBERA, Juan de. (2008). Memoria sobre la conducción de aguas a Madrid. Vicepresidencia primera y Portavocía del Gobierno. Madrid.

SOTELO NAVALPOTRO, José Antonio (2001). Medio Ambiente y medidas de conservación del medio natural de Madrid., Revista Situación., Serie de Estudios Regionales, Madrid., pp. 495-521.

SOTELO NAVALPOTRO, José Antonio y ALCOLEA, M.A. (2005). Unidades fisiográficas, paisajes y espacios naturales protegidos en la región de Madrid. Madrid, revista de arte, geografía e historia., $\mathrm{n}^{\circ}$ 7., pp. 337-372.

SOTELO NAVALPOTRO, J.A. (2007): Medio Ambiente, Desarrollo y Sostenibilidad: Modelos y Políticas de actuación contradictorias: entre lo global y lo local, Oxford University Press.

SOTELO NAVALPOTRO, José Antonio (2009). Las lógicas ilógicas del agua en los contextos de desarrollo. "Road to Copenhagen" Conference sustaining people and the Planet: a fair dial in Copenhagen.

SOTELO PÉREZ, María (2012). Economía y “Huella Hídrica” en España (I). Apuntes de Medio Ambiente. Colegio Doctores y Licenciados. pp.17-21.

SOTELO PÉREZ, María (2013). Territorio y medio ambiente en la Comunidad de Madrid. Las infraestructuras históricas, nuevos paisajes culturales del agua. M+A Revista electrónica de Medio Ambiente, vol. 14, nº1., pp. 87-115.

TORRES, T. et alii. (2005). Génesis y edad del karst del Cerro de la Oliva y la Cueva del Reguerillo (Torrelaguna, Madrid). Libro homenaje al Profesor D. Rafael Fernández Rubio, 225-242

VÁZQUEZ, I. (2009). Estudio geoquímica de suelos y aguas como base para evaluar la contaminación: Relación roca-suelo-agua. Pp.326. ISBN: 978-84-692-1123-6

VINUESA ANGULO, J. (2004). Características demográficas de la Comunidad de Madrid según el Censo de 2001. Instituto de Estadística de la Comunidad de Madrid. pp. 137. 